\title{
Mozart and Super Brains for a Sustaining Future
}

\author{
Konrad Frischeisen* \\ New Frontiers in Science Bildungsgesellschaft mbH, Munich, Germany
}

*Corresponding author: Konrad Frischeisen, New Frontiers in Science BildungsgesellschaftmbH,Munich, New Frontiersin Science, Bildungsgesellschaft $\mathrm{mbH}$ (als gemeinnützig anerkannt), Ungererstr. 76, Germany.
Received Date: December 03, 2018

Published Date: December 12, 2018

\section{Opinion}

Continuing the articles "The Brain as Peace Maker" and "Noble Brains and Nobel-Laureates-Role Models for the $21^{\text {st }}$ Century" the results of split-brain experiments of Nobel laureate Roger Sperry are recalled in memory. They influenced Nobel laureate John Eccles in his research and Nobel laureate Manfred Eigen was paying homage to them in his article, Mozart oder unser Unvermögen, das Genie zu begreifen' ('Mozart or our inability to understand the genius') in his book, Jenseits von Ideolgien und Wunschdenken' ('Beyond ideologies and wishful thinking'). The localization of the different capacities of the human brain according to Sperry's split-brain researches was summarized by Eccles. Eigen uses the overview of Eccles, translated and summarized for this article by the author: (Table 1 )

Table 1: These research results were applied in the creation of a sustaining Magic Flute in dialogue with Boys (B) and Girls (G) and presented here in extracts with a speaker (S), respecting also the life and dignity of animals.

\begin{tabular}{|c|c|}
\hline Dominant Hemisphere & Subdominant Hemisphere \\
\hline Connection to the consciousness & unconscious action \\
\hline verbal, logically constructive & musically, visually \\
\hline comprehending & visual way of capturing \\
\hline analytical, sequential, arithmetic & synthetically, holistic, geometric \\
\hline
\end{tabular}

Speaker (S): Sustaining Life, how human health depends on biodiversity' edited by Eric Chivian and Aaron Bernstein, was presented in IMPRS Interdisciplinary Symposium 2010, New Frontiers In Science" by Prof. Bernstein, Medical School, Harvard University, see the painting of Katharina as result of well cooperating hemispheres of young human brains, participating in the creation of a sustainable Magic Flute, inspired by Mozart, Asclepius and Haydn's oratorium ,The Creation' Introduction, Nr.1, Tamino, prince, in costumes of the Far East, coming to Egypt: 'Help me, otherwise I am lost (...)' (Figure 1)

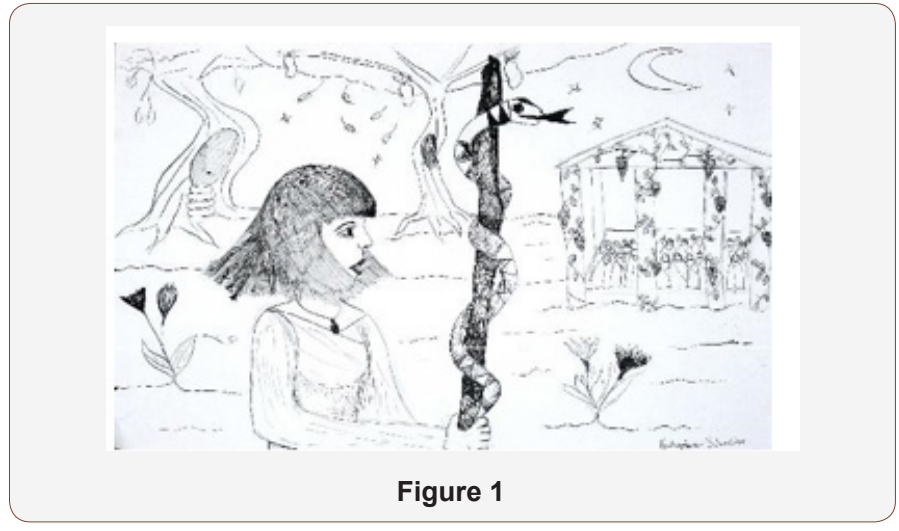

G: He loses consciousness, as a serpent approaches. He seems to be strange in Egypt. Let us look for a wand.

S: In memory and respect of Asclepios, venerated in the antiquity in the theatre of Epidauros, one of three girls takes a wand in order to let the serpent wind itself around the wand. (New Frontiers in Science' lectures, including that of Prof. Aaron Bern-stein, Center for Health and the Global Env., Harvard University, proved, human health is depending on the preservation of biodversity) (Figure 2)

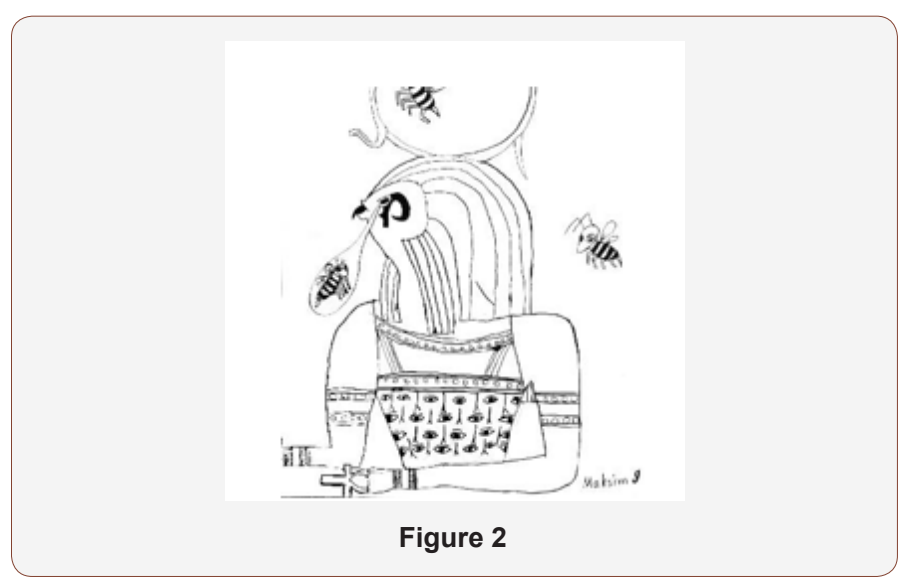

A Girl: The serpent is winding itself around the wand. I carry it to the priests of Asclepius. Nr. 2, Aria, Papageno in a costume of feathers: 'I am the birdcatcher, oh yes, always happy, hopsasa! (...)' 
S: When Tamino awakes from the faint, he is surprised to see Papageno, asking him, who he is, presenting himself as a prince.

Papageno answers, that he is naturally a human being. Pretending to have overwhelmed the serpent, his mouth is padlocked. Tamino receives the Magic Flute and a picture of Pamina, Papageno magic bells, when his mouth is unlocked through grace of the Queen.

Nr. 3, Aria, Tamino:'This picture is so enchantingly beautiful, like no eye has never seen! I feel this picture is divine, my heart so deeply touched as it has ever been. I cannot name it, what could it be? It seems like fire burning in me. Shall this be love? Yes, love alone.'

\section{Nr. 4, Aria, Queen of the Night: (Figure 3)}

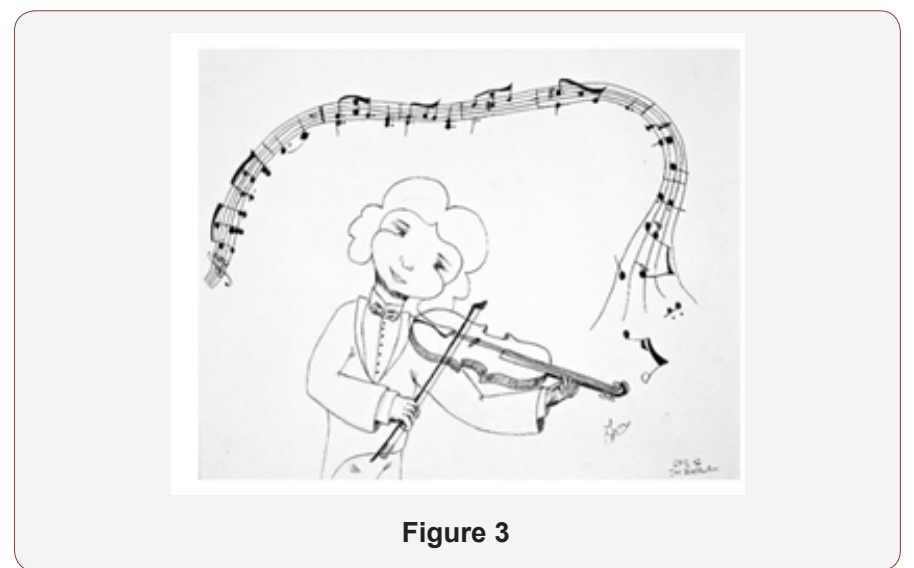

'O tremble not, my dear son-You will go to save her life, rescue her by your endeavour, when I see you victorious, she will be yours forever.'

All: 'Could all liars get locks before their mouths, instead of denunciation and hatred, love and brotherhood would yield a better generation.' (According to Schiller, who was also a medical doctor, brotherhood can foster our healing process.)

Girls: Papageno finds Pamina, gains her confidence with her picture and admits tobe still without woman.

Nr. 7, Duett, Pamina: 'Men, who feel love, will find a good heart.'

Papageno: 'And to transform their longing into beauty is than ladies (p)art and duty.'

S: The boys, supported in this game by graceful girls, present our future, teaching Tamino to be steadfast, patient and silent as a grave. The Queen of the Night is furious and considers the dominating ruler Sarastro as evil, as he had robbed her daughter Pamina and the sun circle of power. In her fury she is requesting from Pamina to kill Sarastro.

In this sustaining version of the magic flute the boys and girls propose to the Queen (of the Night) a reasonable reconciliation with Sarastro.

After some reflection the Queen agrees, if Sarastro gives freedom to her daughter and hands over the sun circle of power.

Girls: In the same time, we can successfully convince Papageno to let the birds free and to become beekeeper, as the bees need help.
He finds a women, calling her Papagena, is soon separated from her, because he cannot keep silence. This is also difficult for Pamina falling in love with Tamino, who comes to the temple to save her from slavery. The boys and the Magic Flute help Tamino to fulfil the difficult laws of the temple, where he is taken as prisoner. The sounds of Tamino's Magic Flute are even attracting wild animals and and help Pamina and Tamino at the end to traverse hells of fire and water. With support of the boys Pamina and Tamino as well as Papageno and Papagena are at last reunited. (With the sounds of Papgeno's magig bells the boys bring Papagena back by aeroplane.)

Speaker: Sarastro is so impressed by the paintings and solutions of the children, by their wisdom, emotional intelligence and responsibility for a harmonious sustainable development, that he gives Pamina freedom, transferring the sun circle of power to her.

The sun, (female in German, Center of our Solar System, discovered by Copernicus, but already praised by Echnaton, Pharaoh Akhenaten, in ancient Egypt and St. Francis of Assisi,) gives light and energy to all human beings, plants and animals as well as to our stage, appearing now as beautiful, graceful and peaceful space ship Earth, embellished by Mozart's brilliant opera in honour of our solar system, (discovered by Copernicus) loved, admired and venerated by all earth children. Pamina, thanking Sarastro gracefully: Let us all cooperate to create a society, based on energy of the sun, in which all children and adults have enough to eat and can develop in freedom and peace Super-Brains in the service of a sustaining future.

\section{Conclusion}

(Pictures of Super-Brains like Columbus, Copernicus, Kepler, Mercator, Leonardo, Michelangelo, Erasmus, Galilei, Mar-low, Milton, Shakespeare, Leibniz, Newton, Fermat, Pascal, Faraday, Maxwell, Bach, Beethoven, Händel, Hayd n, Kant, Goethe, Schiller, the Humboldt, Mozart, Pestalozzi, Maria Montessori, Gandhi, Mira Alfassa, Sri Aurobindo, Pasteur, Tolstoi, Whitman, Vaclav Havel \& Co. may be projected on a screen as well as those of Nobel Laureates like Marie Curie, Banting, Rutherford, Bohr, Einstein, Planck, de Broglie, Raman, Chandrasekhar, Dirac, Heisenberg, Pauli, Schrödinger, Delbrück, Crick, Hershey, Luria, Mandel a, Rita Levi-Montalcini, Barbara McClintock, Francoise Barré-Sinnoussi, Alice Munro,Christiane Nüsslein-Volhard and Donna Strickland, Feynman, Gabor, Gell-Mann, Arber, Binnig, Chu, Cohen-Tannoudji, Eigen, Ernst, Ertl, Fleming, von Frisch, Lorenz, Nadine Gordimer, Haroche, Hänsch, Hell, Huber, Jacob, Kandel, Kastler, Ketterle, Eccles, Pauling, Paz, Prigogine, Pire, Rolland, Schweitzer, Sen, Sperry, Störmer, Tagore, Y ang, Watson, Wieman, Zewail \& Co. and neurologists like Roger Walsh and Viktor Frankl, who proposed a Statue of Responsibility in addition to the Statue of Liberty, suggesting like Goethe to see in others, what they should be, thus helping them to become, what they could be in the upliftment of man to humanity.)- finis.

\section{Acknowledgement}

The author's translations of the original text from Schikaneder's libretto of 'The Magic Flute' is put in inverted commas.

According to Peter v. Matt the Magic Flute is with Shakespeare's Hamlet and Leonardo's Mona Lisa the third great mystery of 
our culture. The children in our version of the Magic Flute are encouraged by Busoni, proclaiming, that Mozart gives with the mystery the solution. Readers and spectators are invited to find the solution, children and author are presenting here. The pictures in this article were painted by children of Munich.

\section{Conflict of Interest}

No conflict of interest. 